\title{
Ontwikkeling van een vragenlijst voor studenten geneeskunde: opvattingen over professioneel gedrag
}

\author{
M.D. Nuijten, J.B. Prins
}

\section{Samenvatting}

Inleiding: In de opleiding geneeskunde vindt onderwijs in professioneel gedrag plaats op basis van de eindtermen in het Raamplan. Vanwege het ontbreken van adequate meetinstrumenten is het effect van onderwijs in professioneel gedrag op opvattingen van studenten over professioneel gedrag nog nauwelijks onderzocht. Doel van dit onderzoek is het ontwikkelen van een betrouwbare en valide vragenlijst over professioneel gedrag die geschikt is voor herhaalde meting bij studenten, zowel in de bachelor-als in de masterfase.

Methode: Bij 42 eindtermen in de categorie 'Persoonlijke aspecten' van het Raamplan 2001 artsopleiding werden zes gedragsbeschrijvingen gemaakt. Deze gedragsbeschrijvingen werden beoordeeld door twee docenten medische psychologie met als doel te komen tot een reductie tot twee gedragsbeschrijvingen per eindterm (een neutrale en een gespiegelde formulering). Dit leidde tot een vragenlijst met 84 items op een vijfpuntsschaal. Deze vragenlijst werd ingevuld door 148 tweedejaarsstudenten geneeskunde en door zeven docent-mentoren. De verkregen data werden vervolgens gebruikt om de vragenlijst te reduceren tot 42 items, één item per eindterm.

Resultaten: De interne consistentie van de antwoorden op de vragenlijst is zowel wat betreft de studenten als de docenten goed. De gemiddelden van de docenten zijn doorgaans hoger dan die van de studenten, maar de verschillen zijn voor $80 \%$ van de items en de subschalen niet significant. Op schaalniveau zijn de verschillen wel significant. De vragenlijst differentieert met name met betrekking tot de range van de scores; deze is voor alle items bij de studenten groter dan bij de docenten.

Conclusie: Voor het meten van de opvattingen van studenten over de toekomstige beroepsuitoefening werd een betrouwbare vragenlijst geconstrueerd. De opvattingen van docenten komen dichter bij de eindtermen van het Raamplan dan die van studenten. De opvattingen van studenten over professioneel gedrag variëren meer dan die van docenten. (Nuijten MD, Prins JB. Ontwikkeling van een vragenlijst voor studenten geneeskunde: opvattingen over professioneel gedrag. Tijdschrift voor Medisch Onderwijs 2010;29(2)117-125.)

\section{Inleiding}

De relevantie van het onderwijs in professioneel gedrag voor artsen komt voort uit de relatief autonome status van de professie, waarbij deze beroepsgroep op grond van gespecialiseerde kennis het recht verworven heeft een eigen gedragscode en beoordelingscriteria op te stellen, en zelf sancties op te leggen aan overtreders van de code. Het behoren tot een specifieke beroepsgroep is gebonden aan professioneel gedrag, dat deels beschreven staat in een gedragscode. De noodzaak van onderwijs in professioneel gedrag blijkt uit Amerikaans onderzoek, waarin aangetoond wordt dat er een sterke relatie is tussen het voorkomen van disciplinaire maatregelen onder praktiserende artsen en eerder vertoond onprofessioneel gedrag tijdens de opleiding geneeskunde. ${ }^{1-3}$ 
In de opleiding geneeskunde vindt onderwijs in professioneel gedrag plaats op basis van de eindtermen in het Raamplan ${ }^{4}$ en het CanMEDS model. ${ }^{5}$ Vanwege het ontbreken van adequate meetinstrumenten is het effect van dit onderwijs op de ontwikkeling van professioneel gedrag van studenten gedurende de opleiding geneeskunde nog nauwelijks onderzocht. Om een geschikt meetinstrument te kunnen ontwikkelen is het in de eerste plaats van belang te weten hoe professioneel gedrag in de opleiding geneeskunde wordt gedefinieerd. Professioneel gedrag van artsen betreft observeerbaar gedrag dat voortvloeit uit opvattingen over de beroepsuitoefening en waarin de normen en waarden van de beroepsgroep zichtbaar zijn; het ijkpunt is het welzijn van de patiënt. ${ }^{6}$

Professioneel gedrag is waarneembaar in de wijze waarop wordt omgegaan met taken/werk, met anderen en met zichzelf. Daar professioneel gedrag gekoppeld is aan de beroepspraktijk is dit bij studenten het beste te observeren en te beoordelen tijdens de coschappen in de masterfase van de studie. Om professioneel gedrag te kunnen ontwikkelen en zo nodig bij te kunnen sturen, is het belangrijk om reeds in de bachelorfase een aantal voorspellende factoren boven tafel te krijgen. Concrete voorbeelden zijn een verregaande terughoudendheid, faalangst, weinig sociaal gevoel, het niet kunnen onderscheiden van hoofden bijzaken en onvolwassen gedrag. ${ }^{7}$

Het opsporen en beïnvloeden van professioneel gedrag is mogelijk door een combinatie van gedragsbeoordelingen en het in kaart brengen van opvattingen van de studenten. Opvattingen zijn gekoppeld aan zowel persoonlijke waarden en normen als aan gevoelens en voornemens en hebben een sturende werking op het feitelijke gedrag in de praktijk. De integratie van waarden en normen van de beroepsgroep (zoals weerspiegeld in de eind- termen van het Raamplan) met de persoonlijke waarden en normen, is een belangrijk onderdeel van de medisch professionele vorming. Medisch professionele vorming is een proces van jaren, waarin de aankomende arts een eigen, authentieke stijl ontwikkelt om zijn kennis en vaardigheden in dienst te stellen van een goede gezondheidszorg. Gedragsinstructie alleen is niet voldoende om dit te bewerkstelligen. ${ }^{6}{ }^{8}$ Zo blijkt uit Canadees onderzoek $^{9}$ dat al in de periode voorafgaand aan de opleiding en in het eerste jaar een set waarden en normen ten aanzien van de beroepsuitoefening wordt gevormd, die zich nog moeilijk laat beïnvloeden door de latere colleges ethiek.

In het medisch onderwijs in Nederland is inmiddels ruime ervaring opgedaan in het onderwijs in en het beoordelen van professioneel gedrag. In Groningen wordt studentgedrag in werkgroepen beoordeeld door tutoren met behulp van een beoordelingslijst. ${ }^{10}$ Maastricht heeft de eerste stappen gezet om de formatieve en de summatieve aspecten (het leren en het toetsen) in het medisch praktisch onderwijs te concentreren in vaste groepen. Dit maakt een longitudinale studie naar de professionele ontwikkeling van studenten mogelijk. ${ }^{11}$

Belangrijk is om vast te stellen welke elementen van professioneel gedrag in welke onderwijsactiviteit besproken en getoetst kunnen worden. De voorkeur gaat uit naar kleinschalige activiteiten, waarin jaargenoten en docenten de student meerdere malen zien functioneren. ${ }^{12}$ Een beoordelingssysteem van professioneel gedrag door studiegenoten behoort ook tot de mogelijkheden maar wel onder een aantal voorwaarden, zoals anonimiteit, directe feedback, formatief gebruik in een ondersteunende omgeving en met aandacht voor zowel professioneel als onprofessioneel gedrag. ${ }^{13}$ 
In de ontwikkelingsfase tijdens de opleiding geneeskunde kan men nog niet van alle studenten een volwassen professionaliteit verwachten met het vermogen gedrag in een context te plaatsen of zich in te zetten voor de gemeenschap c.q. voor het welzijn van anderen. ${ }^{14}$ In dit proces is de rol van mentoren van groot belang, met name het fungeren als rolmodel, het leren kennen van de ongeschreven code (het verborgen curriculum van professionaliteit), het geven van sociaal-emotionele steun en het inzetten van diens contacten ten gunste van de student. ${ }^{15}$ In een kwalitatieve studie onder tutoren ${ }^{16}$ is een aantal factoren in kaart gebracht die de professionele ontwikkeling van studenten geneeskunde positief of negatief kunnen beïnvloeden. Het betreft lesgeven/krijgen, reflectie, integratie in het studieprogramma, vroege patiëntcontacten, het verborgen curriculum, werken in kleine groepen, dezelfde tutor over een langere periode en het gebruik van een portfolio.

In de VS is een van de eerste betrouwbare en valide instrumenten ontwikkeld voor het meten van de attitude van studenten ten opzichte van professionaliteit. ${ }^{17}$ In dit onderzoek willen wij de vraag beantwoorden of het ook in Nederland mogelijk is om op basis van de eindtermen in het Raamplan uit de categorie 'Persoonlijke aspecten' te komen tot een betrouwbare en valide vragenlijst waarmee de opvatting van studenten over professioneel gedrag van artsen gemeten kan worden. De vragenlijst werd ingevuld door studenten, assistenten in opleiding en docenten met een medische achtergrond. De opvattingen over professioneel gedrag bleken al in een vroeg stadium van de opleiding in kaart gebracht te kunnen worden. Het belang van een Nederlandse vragenlijst vloeit voort uit het feit dat professioneel gedrag niet alleen beroepsgebonden maar ook cultuurgebonden is.
Doel van dit onderzoek is het ontwikkelen van een vragenlijst aan de hand waarvan de opvatting van studenten over professioneel gedrag gemeten kan worden en die tevens geschikt is voor herhaalde meting in zowel de bachelor- als de masterfase. Op termijn zou met een dergelijke vragenlijst de ontwikkeling van de opvattingen gevolgd kunnen worden gedurende alle studiejaren en onderzocht kunnen worden of er een verband is tussen de opvattingen over professioneel gedrag tijdens de bachelorfase en het geobserveerde professioneel gedrag tijdens de coschappen.

\section{Methode \\ Opzet}

De vragenlijst werd ontwikkeld door de afdeling Medische Psychologie van het UMC St. Radboud te Nijmegen. Bij 42 eindtermen uit het Raamplan 2001 in de categorie 'Persoonlijke aspecten' (artspatiëntrelatie, persoonlijk functioneren, wederzijdse beïnvloeding werk-privéleven) werden zes concrete gedragsbeschrijvingen gemaakt die werden gepresenteerd als stellingen met als doel de impliciete opvattingen van studenten geneeskunde over de beroepsuitoefening van artsen zichtbaar te maken. Deze gedragsbeschrijvingen werden vervolgens door twee docenten medische psychologie - beiden met ruime ervaring in het onderwijs geneeskunde - beoordeeld op begrijpelijkheid en relevantie. Het doel van deze beoordeling was kwaliteitsverbetering van de lijst en een reductie tot twee gedragsbeschrijvingen per eindterm. Ter voorkoming van sociaal wenselijke antwoorden werd per item een bevestigende en een ontkennende beschrijving gekozen. Zo ontstond een vragenlijst met 84 items, te scoren op een vijfpuntsschaal ( $1=$ helemaal oneens, $2=$ =neens, 3 =neutraal, $4=$ =ens, $5=$ helemaal eens en omgekeerd voor de 
ontkennende stellingen). Deze vragenlijst werd ingevuld door 148 tweedejaarsstudenten geneeskunde en door zeven docent-mentoren (praktiserende artsen en medisch specialisten). Het doel van het invullen van de lijst door docent-mentoren was zowel het opsporen van differentiatie tussen de antwoorden van studenten en docent-mentoren als het krijgen van inhoudelijke feedback om het instrument verder te ontwikkelen.

\section{Analyse}

Op grond van de vergaarde gegevens van studenten en docent-mentoren op de vragenlijst met 84 items werd in de eerste plaats onderzocht of het mogelijk was de lijst in te korten met behoud van interne consistentie. Daarvoor werd bepaald wat de interne consistentie van de antwoorden van elk van beide steekproeven was, welke beweringen (items) de interne consistentie van de lijst positief dan wel negatief beïnvloedden, en of er verschil met betrekking tot de interne consistentie was tussen de neutrale en gespiegelde items; ook werd gekeken of het mogelijk was de subparagrafen van het Raamplan als subschalen te gebruiken.

Ten tweede werd nagegaan of het mogelijk was de lijst zo te construeren dat deze differentieert tussen studenten en docenten. Verschillen tussen studenten geneeskunde en docent-mentoren werden berekend in de gemiddelden van hun scores en in de standaardafwijkingen van deze gemiddelden. Verder werden verschillen in de range van de scores tussen studenten en docent-mentoren bepaald en werd vastgesteld welke items beter beoordeeld worden door studenten dan door docenten.

Tot slot werden verschillen gezocht tussen de items die bijdragen aan de interne consistentie van de antwoorden van studenten en de items die bijdragen aan de interne consistentie van de antwoorden van docent-mentoren. Van de antwoorden van deze twee onafhankelijke steekproeven werden de interne consistentie Cronbach's alpha, de totaalcorrelatie en de alpha voor de schaal berekend als dit item wordt weggelaten. Twee verkorte lijsten van 42 items werden gecreëerd door van elke twee gedragsbeschrijvingen per item slechts die gedragsbeschrijving te handhaven die het meest bijdroeg aan de interne consistentie van respectievelijk de docentgegevens en de studentgegevens. Dit resulteerde in een lijst met vragen die door de docent-mentoren het meest consistent beantwoord werden en een lijst met vragen die door de studenten het meest consistent beantwoord werden. Deze twee lijsten hadden 20 items gemeenschappelijk. Een belangrijke reden voor deze bewerking was het uitgangspunt dat alle eindtermen uit het gekozen deel van het Raamplan vertegenwoordigd moesten zijn.

De interne consistentie van de antwoorden van de docent-mentoren werd gekozen als uitgangspunt voor de validiteit van de vragenlijst. Daarmee werd de lijst met de 42 items waarop docenten het meest consistent antwoordden, de definitieve lijst. Om vast te stellen of deze vragenlijst differentieerde tussen studenten en docenten werden de frequenties van beide steekproeven op alle 42 items berekend, alsmede de range, het gemiddelde en de standaarddeviatie. Tevens werd een T-toets uitgevoerd voor de verschillen in gemiddelden van zowel de scores als de range tussen de twee onafhankelijke steekproeven van studenten en docent-mentoren en een F-toets voor de verschillen in standaarddeviatie.

\section{Resultaten}

\section{Interne consistentie}

De oorspronkelijke lijst van 84 items laat voor de studenten een hogere Cronbach's alpha zien dan voor de docent-mentoren 
Tabel 1. Cronbach's alpha's van de neutrale vragen en gespiegelde vragen in de totale vragenlijst in de oorspronkelijke en definitieve versie.

\begin{tabular}{ccccccc}
\hline & \multicolumn{3}{c}{ Oorspronkelijke lijst van $\mathbf{8 4}$ items } & \multicolumn{3}{c}{ Definitieve lijst van $\mathbf{4 2}$ items } \\
\hline & $\begin{array}{c}\text { Totaal } \\
(84)\end{array}$ & $\begin{array}{c}\text { Neutrale } \\
\text { vragen (42) }\end{array}$ & $\begin{array}{c}\text { Gespiegelde } \\
\text { vragen (42) }\end{array}$ & $\begin{array}{c}\text { Totaal } \\
(42)\end{array}$ & $\begin{array}{c}\text { Neutrale } \\
\text { vragen }\end{array}$ & $\begin{array}{c}\text { Gespiegelde } \\
\text { vragen }\end{array}$ \\
Studenten & .85 & .77 & .80 & .77 & .60 & .75 \\
Docenten & .78 & .78 & .49 & .88 & .78 & .84 \\
\hline
\end{tabular}

(Tabel 1). De interne consistentie van de subschalen uit het Raamplan is overwegend laag: voor studenten variërend van .61 voor subschaal 1 ( 24 items), .81 voor subschaal 2 (56 items), en .19 voor de subschaal met slechts vier items. De waarden voor de docenten zijn: .44 voor subschaal $1, .55$ voor subschaal 2 en .02 voor subschaal 3. De interne consistentie van de docentgegevens is beduidend lager voor de gespiegelde vragen dan voor de ongespiegelde vragen. Voor de studenten is het verschil te verwaarlozen. De definitieve lijst van 42 items die door de docenten het meest consistent werden beantwoord, vertoont wat betreft de beantwoording door de studenten een iets lagere interne consistentie. De interne consistentie van deze vragenlijst is voor beide steekproeven goed.

\section{Onderscheidend vermogen van de vragenlijst}

In de definitieve vragenlijst zijn de verschillen tussen de gemiddelden van docent-mentoren en studenten op itemniveau en op subschaalniveau voor $80 \%$ niet significant. Op itemniveau zijn de verschillen significant voor slechts negen van de 42 items (zie Tabel 2). De standaarddeviaties van deze gemiddelden verschillen voor vier van de 42 items significant. Twaalf van de 42 vragen zijn door de studenten beter be- antwoord, waarvan één vraag significant beter.

Op het niveau van de subschaal zijn de verschillen tussen de gemiddelden van docenten en studenten significant bij slechts één van de vijf subschalen: persoonlijk functioneren; medisch handelen. Op schaalniveau zijn de verschillen in gemiddelden van studenten en docenten wel significant (zie Tabel 3). Dit verschil was niet significant in de oorspronkelijke lijst.

Voor alle items is de gemiddelde range bij de studenten groter dan bij de docenten. De gemiddelde range van de studentenscores (3.45) verschilt op schaalniveau significant $(\mathrm{p}<0.001)$ van de gemiddelde range van docentenscores (1.71). Ook de standaarddeviaties bij deze gemiddelden verschillen significant $(\mathrm{p}<0.05)$ voor studenten (.63) en docenten (.94).

\section{Conclusie}

Een vragenlijst met 42 items voor het meten van opvattingen over de beroepsuitoefening van studenten, met een goede interne consistentie, werd geconstrueerd. Dit geeft een goede indicatie voor de betrouwbaarheid, hoewel de test-hertest betrouwbaarheid in dit onderzoek nog niet werd bepaald.

De belangrijkste investeringen in de validiteit van de vragenlijst zijn achtereenvolgens het feit dat de items gebaseerd 
Tabel 2. Overzicht van negen items, waarvan de gemiddelde scores van studenten en docenten significant verschillen.

\begin{tabular}{|c|c|c|c|c|}
\hline \multirow[b]{2}{*}{ Item } & \multirow[b]{2}{*}{ vraag } & \multicolumn{2}{|c|}{$M$} & \multirow[b]{2}{*}{$p$} \\
\hline & & student & docent & \\
\hline 49. & $\begin{array}{l}\text { Wanneer een patiënt vertelt verliefd op de arts te zijn dan } \\
\text { reageert de arts daar niet op }\end{array}$ & 3.78 & 4.71 & $.007^{* *}$ \\
\hline 23. & $\begin{array}{l}\text { Wanneer een coassistent de instructie van de arts niet goed } \\
\text { opvolgt is de arts verantwoordelijk voor het eindresultaat }\end{array}$ & 3.51 & 4.14 & $.003^{* *}$ \\
\hline 05. & $\begin{array}{l}\text { Een arts is zich bewust van de verleiding dat hij geneesmiddelen, } \\
\text { waarvan de fabrikant op congressen relatiegeschenken uitdeelt, } \\
\text { net iets vaker voor zal schrijven }\end{array}$ & 3.09 & 4.14 & $.000^{* * *}$ \\
\hline 08. & $\begin{array}{l}\text { Bij complicaties waarschuwt de arts de patiënt of de familie } \\
\text { pas als hij het probleem heeft opgelost }\end{array}$ & 4.16 & 4.8 & $.025^{*}$ \\
\hline 26. & $\begin{array}{l}\text { De arts maakt bij iedere patiënt een afweging van de voor- } \\
\text { en nadelen van een behandeling }\end{array}$ & 4.38 & 4.86 & $.014^{*}$ \\
\hline 58. & $\begin{array}{l}\text { De arts houdt zich in zijn beroep niet bezig met zijn gevoelens } \\
\text { over existentiële problemen, want dat behoort tot het privé- } \\
\text { domein }\end{array}$ & 3.55 & 4.57 & $.001^{* *}$ \\
\hline 43. & $\begin{array}{l}\text { De arts doet er goed aan veel aan het woord te zijn in het } \\
\text { multidisciplinair team, zodat iedereen weet dat hij zeer } \\
\text { betrokken is }\end{array}$ & 3.63 & 4.29 & $.029^{*}$ \\
\hline 84. & $\begin{array}{l}\text { De arts die van alle markten thuis is en zoveel mogelijk } \\
\text { behandelingen zelf uitvoert handelt multidisciplinair }\end{array}$ & 3.74 & 4.57 & $.009^{* *}$ \\
\hline 56. & $\begin{array}{l}\text { Wanneer een arts thuiskomt van zijn werk heeft hij nog energie } \\
\text { over voor zijn privérelaties en zijn hobby's }\end{array}$ & 4.06 & 3.29 & $.011^{*}$ \\
\hline
\end{tabular}

${ }^{*} p<0.05 ;{ }^{* *} p<0.01 ;{ }^{* * *} p<0.001 ;$ tweezijdig

Tabel 3. Gemiddelde scores van studenten en docenten op de subschalen in de categorie 'Persoonlijke aspecten' van het Raamplan 2001 en verschillen in gemiddelden.

\begin{tabular}{lcrrrr}
\hline \multicolumn{5}{c}{$\mathrm{N}$} & \multicolumn{3}{c}{$\mathrm{M}$} & \\
\hline Subschaal & items & student & docent & t-waarde & P \\
\hline Arts-patiënt relatie & 12 & 47.20 & 48.57 & -.995 & .321 \\
PF pers. eigenschap & 9 & 34.54 & 36.57 & -1.933 & .055 \\
PF medisch handelen & 9 & 35.34 & 38.14 & -2.745 & $.007^{* *}$ \\
PF teamverband & 10 & 38.67 & 40.86 & -1.916 & .057 \\
Invloed werk-privé & 2 & 7.69 & 7.14 & 1.252 & .213 \\
Totaal & $\mathbf{4 2}$ & $\mathbf{1 6 3 . 3 7}$ & $\mathbf{1 7 1 . 2 9}$ & $\mathbf{- 2 . 0 9 6}$ & $.038^{*}$ \\
\hline
\end{tabular}

${ }^{*} p<0.05 ;{ }^{* *} p<0.01$ 
werden op het Raamplan, dat de scores van docent-mentoren als norm werden genomen en dat de helft van de vragen gespiegeld werd, dit om sociaal wenselijke antwoorden te voorkomen. Het Raamplan is een goede bron gebleken voor het ontwerpen van een meetinstrument voor de opvattingen over professioneel gedrag. Dit onderzoek heeft geen resultaten opgeleverd die op het tegendeel wijzen. Bovendien verhoogt een dergelijke keuze de acceptatie van het meetinstrument door de medische beroepsgroep. De aanname dat subparagrafen van het Raamplan als subschalen van de vragenlijst dienst konden doen moest herroepen worden op grond van de geringe interne consistentie van de subschalen.

Uit het Raamplan werd de categorie 'Persoonlijke aspecten' gekozen omdat deze de meeste elementen van professioneel gedrag bevat. Er was een zeker spanningsveld tussen het doel om alle eindtermen af te dekken en het doel de interne consistentie zo maximaal mogelijk te maken. In het laatste geval waren niet meer alle eindtermen gedekt. Dit werd niet acceptabel gevonden.

Het belang van differentiatie in de antwoorden van studenten en docent-mentoren is gelegen in de aanname dat de opvattingen van docent-mentoren verder geëvolueerd zijn dan die van studenten en dat er voor de studenten nog wat te leren is. Dat zou zichtbaar moeten zijn in een verschil tussen de gemiddelden van studenten en docent-mentoren en in een kleinere standaarddeviatie bij docentmentoren dan bij studenten. Verwacht mag worden dat deze verschillen in de loop van de opleiding kleiner zullen worden. Wel moet hier worden opgemerkt dat het aantal van zeven docent-mentoren erg weinig is. Een herhalingsonderzoek onder een groot aantal docent-men- toren is aan te bevelen, maar kon in het kader van dit onderzoek niet meer worden gerealiseerd.

De gemiddelden van de docenten waren doorgaans hoger dan die van de studenten, maar de verschillen waren voor het merendeel van de items en de subschalen niet significant. Op schaalniveau zijn de verschillen tussen studenten en docenten wel significant, hetgeen een bevestiging is van de keuze om alle items vertegenwoordigd te hebben in de schaal. De vragenlijst differentieerde met name met betrekking tot de range van de antwoorden. Het verschil in gemiddelden tussen de docentmentoren en de studenten op schaalniveau was niet significant in de oorspronkelijke lijst, maar wel in de definitieve lijst. Dit betekent dat de verkorte lijst differentieert tussen studenten en docent-mentoren en dat het inkorten ook in dit opzicht goed heeft gewerkt. Dit geldt in nog sterkere mate voor de range: het verschil in de gemiddelden van de range op schaalniveau tussen de studenten en de docent-mentoren was groter voor de definitieve lijst dan voor de oorspronkelijke lijst.

Het gevolg van de beslissing om bij het inkorten van de vragenlijst de interne consistentie van de antwoorden van de docenten als norm te nemen had diverse gevolgen. De beweringen waarop studenten consistent antwoorden zijn inhoudelijk niet altijd dezelfde als de beweringen waarop de docent-mentoren een consistent antwoord geven. Bij 22 items lijken de bevestigende en de ontkennende gedragsbeschrijvingen de studenten en de docent-mentoren te verdelen. Hier komen verschillen in referentiekader tussen beide groepen aan het licht. Informatie die mogelijk belangrijk kan zijn voor het leerproces bij professioneel gedrag wordt door de keuze van de docent-mentoren als norm 
niet zichtbaar. Docent-mentoren antwoordden bijvoorbeeld meer consistent dan studenten op de beschrijving:

"Een arts is zich bewust van de verleiding dat hij geneesmiddelen, waarvan de fabrikant op congressen relatiegeschenken uitdeelt, net iets vaker voor zal schrijven".

Studenten antwoordden meer consistent op de gedragsbeschrijving bij het zelfde item waarin een ontkennend element staat:

\section{"Als een arts via zijn werkcontacten een paar interessante nevenfuncties kan krijgen dan is daar niets op tegen."}

In beide gevallen zijn de antwoorden van de docent-mentoren meer conform de eindtermen. Wat de verschillen zijn tussen de vragen die wel een betrouwbaar antwoord aan de studenten ontlokken, maar niet aan de docenten (en vice versa) kan nog aan een kwalitatieve analyse onderworpen worden. Om tot subschalen te komen die intern consistent zijn, is een factoranalyse een wenselijke optie. Daarmee wordt de vragenlijst ook vergelijkbaar met het meetinstrument uit de $\mathrm{VS}^{25}$ en krijgt de vragenlijst inhoudelijk meer diepte.

Uit het literatuuronderzoek bleek dat de opvattingen van bachelorstudenten geneeskunde over de beroepsuitoefening invloed hebben op het professioneel gedrag in de masterfase ${ }^{6 \text { 8-9 }}$ en dat dit gedrag gerelateerd is aan het professioneel gedrag in de latere beroepsuitoefening. ${ }^{1-3}$

De bevindingen uit het onderzoek geven aanleiding om de vragenlijst te gaan gebruiken in vervolgonderzoek. Het laten invullen van de definitieve vragenlijst door grotere groepen docent-mentoren en medisch specialisten in (academische) medische centra zou kunnen leiden tot een verbetering van de validiteit van de vragenlijst. Bij verder onderzoek onder studenten geneeskunde verdient het aanbeveling de vragenlijst twee maal te laten invullen door dezelfde studenten van de steekproef voor het vaststellen van de testhertest betrouwbaarheid. Ook zouden twee gematchte steekproeven van bachelor studenten met elkaar vergeleken kunnen worden. Verdere verbetering van de psychometrische kwaliteiten van de vragenlijst zal bijdragen aan het uiteindelijke doel om de ontwikkeling van professioneel gedrag van studenten geneeskunde tijdens hun opleiding longitudinaal te volgen.

\section{Literatuur}

1. Papadakis MA, Teherani A, Banach MA, Knettler TR, Rattner SL, et al. Disciplinary action by medical boards and prior behavior in medical school. New Engl J of Med 2005; 353 (25):2673-82.

2. Stern DT, Frohna AZ, Gruppen LD. The prediction of professional behaviour. Med Educ 2005; 39:75-82.

3. Papadakis MA, Arnold GK, Blank LL, Holmboe ES, Lipner RS. Performance during internal medicine residency training and subsequent disciplinary action by state licensing boards. Ann Intern Med 2008;148 (11): 869-877.

4. Metz JCM, Verbeek-Weel AMM, Huisjes HJ. Raamplan 2001 artsopleiding. Bijgestelde eindtermen van de artsopleiding. UMC Nijmegen 2001. [Blueprint 2001, training of doctors in the Netherlands. Adjusted objectives of undergraduate medical education in the Netherlands, UMC Nijmegen].

5. Frank JR, Jabbour M, Tugwell P, et al. Skills for the new millennium: report of the societal needs working group, CanMEDS 2000 Project. Annals Royal college of Physicians and Surgeons of Canada 1996;29:206-216.

6. Spaendonck KPM van. Attitude versus professioneel gedrag. Tijdschrift voor Medisch Onderwijs 2006; 25 (6):285-290. [Attitude versus professional behaviour. Netherlands Journal of Medical Education 2006;25;285-290].

7. Postma CT, Thoben A, Timmermans L, Spaendonck K van. Horken en huilebalken, onprofessioneel gedrag tijdig signaleren. Med Contact 2006, 61(21): 883-885. [Dorks and wimps, timely identification of unprofessional behaviour. Medical Contact 2006;61(21):883-885].

8. Spaendonck KPM van, Timmermans LM, Thoben AJ en Postma C. Professioneel gedrag, begripsbe- 
paling, onderwijs en toetsing. Onderwijsinstituut UMC St. Radboud Nijmegen, januari 2006: 28-29. [Professional behaviour: definition, teaching and assessment. Education Institute, january 2006].

9. Patenaude J, Niyonsenga T, Fafard D. Changes in students' moral development during medical school: a cohort study. CMAJ 2003;168 (7):840-844.

10. Penninga M, Schönrock-Adema J, Cohen-Schotanus J. Beoordeling van studentgedrag: de ervaringen van tutoren. Tijdschrift voor Medisch Onderwijs 2005;24 (5):204-211. [Assessing students' professional behaviour: tutors' experiences. Netherlands Journal of Medical Education 2005;24(5):204-211].

11. Mook WNKA, Luijk SJ van, Fey-Schoenmakers MJG, Oudhuis GJAPM, Gulikers MTH. Schuwirth LW, Vleuten CPM van der. Bespreking en beoordeling van professioneel gedrag aan de Faculteit Geneeskunde te Maastricht. Tijdschrift voor Medisch Onderwijs 2007;26 (5): 237-246. [Evaluation and assessment of professional behaviour at the Faculty of Health, Medicine and Life Sciences, Maastricht. Netherlands Journal of Medical Education 2007;26(5):237-246].

12. Mook WNKA van, Luijk SJ van, Oudhuis GJAPM, Gulikers MTH, Schuwirth LW, Vleuten CPM van der. Professioneel gedrag in de opleiding geneeskunde. Tijdschrift voor Medisch Onderwijs 2007; 26 (4): 174-183. [Professional behaviour in medical education. Netherlands Journal of Medical Education 2007;26(4):174-183].

13. Arnold L, Shue CK, Kalishman S, Prislin M, Pohl C, et al. Can there be a single system for peer assessment of professionalism among medical students? A multi-institutional study. Acad Med 2007; 82 (6):578-586.
14. Hilton SR and Slotnick HB. Proto-professionalism: how professionalization occurs across the continuum of medical education. Med Educ 2005;39:58-65.

15. Rose GL, Rukstalis MR, Schuckit MA. Informal mentoring between faculty and students. Acad Med 2005; 80 (4):344-348.

16. Goldie J, Dowie A, Cotton P, Morrison J. Teaching professionalism in the early years of a medical curriculum: a qualitative study. Med Educ 2007;41: 610-617.

17. Blackall GF, Melnick SA, Shoop GH, George J, Lerner SM, et al. Professionalism in medical education: the development and validation of a survey instrument to assess attitudes towards professionalism. Med Teach 2007; 29:58-62.

\section{De auteurs:}

Prof. dr. J.B. Prins is klinisch psycholoog, afdelingshoofd Medische Psychologie en principal lecturer in het UMC st Radboud, Nijmegen.

Drs M.D. Nuijten is GZ-psycholoog en was ten tijde van dit onderzoek aangesteld bij Medische Psychologie voor ontwikkeling en onderzoek van onderwijs in het curriculum geneeskunde.

\section{Correspondentieadres:}

Mevr. prof. dr. J.B. Prins, afdeling Medische Psychologie,UMC St Radboud, postbus 9101, 6500 HB Nijmegen.E-mail: j.prins@umcn.nl

Belangenconflict: geen gemeld

Financiële ondersteuning: geen gemeld

\section{Summary}

Introduction and aim: The teaching of professionalism in undergraduate medical education is based on the final objectives of Blueprint 2001, training of doctors in the Netherlands. Few studies have addressed the effects of professionalism education on students' professional behaviour due to a lack of evaluation instruments. We aimed to develop a reliable and valid questionnaire that can be used for repeated evaluation of medical students' professional behaviour during the bachelor and master phases of the curriculum.

Method: Six descriptions of professional behaviour were developed for each of the 42 final objectives in the category 'personal aspects', listed in Blueprint 2001. Based on the evaluations of two teachers of professionalism, the list was reduced to 84 descriptions (two per objective, framed positively and negatively, respectively). The resulting 84 item questionnaire with five-point answer scales was completed by 148 second year medical students and seven teachermentors. Based on the results the list was reduced to 42 items, one per final objective.

Results: The questionnaire had good internal consistency both for the student and the teacher data. The teacher-mentors gave lower ratings compared to the students, but the differences were not significant for $80 \%$ of the items and the subscales. However, there were significant differences at scale level. The score range was wider for the students compared to the teachers.

Conclusion: We developed a reliable questionnaire for measuring students' opinions on professional behaviour. The opinions of the teachers were closer to the final objectives of Blueprint 2001 than those of the students, which showed greater variation. (Nuijten MD, Prins JB. Development of a questionnaire to elicit Opinions on Professional Behaviour from medical students. Netherlands Journal of Medical Education 2010;29(2):117-125.) 